\title{
The Effects of Conscientiousness, Agreeableness, Organizational Climate, and Job Satisfaction on Lecturerôs Commitment at One Public University in Jambi
}

\author{
Ali Idrus \\ Faculty of Education, Jambi University \\ 36361, Jambi, Indonesia
}

\begin{abstract}
The purposes of this research were to verify the personality traits consisting of conscientiousness and agreeableness as personal factors along with job satisfaction and organizational climate as the environmental factors affect organizational commitment and to compare the organizational commitment of lecturers at one public university in Jambi. A questionnaire was used as a research instrument to collect the data from 140 lecturers. Data were analyzed by using descriptive statistics and path analysis to analyze the effects of conscientiousness, agreeableness, job satisfaction and organizational climate on organizational commitment. The results of the study indicated that conscientiousness, agreeableness, and job satisfaction had direct effects on the organizational commitment, while organizational climate had indirect effects. Additionally, the organizational climate had direct effects on job satisfaction. These findings indicated that personal and environmental factors affect organizational commitment in an organization.
\end{abstract}

Keywords: conscientiousness and agreeableness; job satisfaction; organizational commitment; organizational climate.

\section{INTRODUCTION}

It is undoubted that education matters in the human and economic development. Knowledge (leak) has become the most important factor in the economic development [1] and ñInvestments in tertiary education generate major external benefits that are crucial for knowledge-driven economic and social developmentò (p. xxi) [2]. Tertiary education or higher education has a variety of purposes such as for effective creation, dissemination, and application of knowledge and for building technical and professional capacity. University as one of the forms of higher education has a central role to achieve those purposes.

However, those purposes will only be achieved through having highly quality and committed faculty members or lecturers. Commitment is related to someoneôs attachment to one organization where she or he works. There are three components of commitment, namely affective, continuous, and normative commitment [3]. For affective commitment, it is connected with the existence of emotional attachment and involvement of employees in their organization, while continuous commitment is related to the awareness of the costs associated with leaving the organization. Additionally, normative commitment is connected with a feeling of obligation to continue employment [3].

In this study, lecturersôcommitment is related to how they are committed to their organization (university), which is influenced by their behaviors such as their attendance, academic atmosphere including their interactions with students, colleagues, deans, or rector, and their academic productivity including doing research, writing research articles, and participating in the development of their faculty and university. The existence of lecturersôcommitment at any university may become the standards of the effectiveness and quality of a university as a form of higher education.

One of the important factors related to the organizational commitment is personality (Conscientiousness dan Agreeableness). The appropriateness or the match between lecturersô personality and their job (person-job fit) is one of the factors influencing lecturersô commitment to their university. The more appropriate the lecturersôpersonality, the higher the lecturersô commitment to their university [3]. The other two factors are related to job satisfaction and organizational climate. The purposes of this research were to verify the personality traits consisting of conscientiousness and agreeableness as personal factors along with job satisfaction and organizational climate as the environmental factors affect organizational commitment and to compare the organizational commitment of lecturers at one public university in Jambi.

\section{METHODS}

\section{A. Research site and participants}

This study was conducted at one public university in Jambi, Sumatra, Indonesia. The participants of this study were 140 lecturers consisting of 55 percent of male lecturers and 45 percent of female lecturers from five faculties. The age ranged from 30 to 55 years. In terms of working experience, all have worked for at least three years at the research site. All 
participants held at least an undergraduate degree and masterôs degree. The 140 participants were recruited through a variety of networking sources and permission from the authorities was also acquired.

\section{B. Data collection and analysis}

This study used a survey questionnaire in order to examine the personality traits consisting of conscientiousness and agreeableness as personal factors along with job satisfaction and organizational climate as the environmental factors affect organizational commitment and to compare the organizational commitment of lecturers at one public university in Jambi. The survey questionnaires were personally administered to each lecturer at one public university in Jambi, Sumatra, Indonesia. The questionnaires consisted of (1) the organizational commitment with 42 statements (e.g. I like working at this university), (2) the job satisfaction with 30 statements (e.g. the working environment encourages me to work comfortably), (3) the agreeableness with 25 statements (e.g. I feel happy that the sense of togetherness encourages the spirit of work at my university), (4) the conscientiousness with 30 statements (e.g. I prepare myself for doing my duties at my faculty), and (5) the organizational climate with 36 statements. A Likert scale (from ñstrongly disagreeò to ñstrongly agreeò) was used to measure the personality traits consisting of conscientiousness and agreeableness as personal factors along with job satisfaction and organizational climate as the environmental factors affect organizational commitment and to compare the organizational commitment of lecturers at one public university in Jambi. Data were analyzed by using descriptive statistics and path analysis to analyze the effects of conscientiousness, agreeableness, job satisfaction and organizational climate on organizational commitment.

\section{RESUlTS AND DisCUSSIONS}

The purposes of this research were to examine the personality traits consisting of conscientiousness and agreeableness as personal factors along with job satisfaction and organizational climate as the environmental factors affect organizational commitment and to compare the organizational commitment of lecturers at one public university in Jambi. The following were the variable descriptions of the data obtained from the questionnaires.

In terms of the conscientiousness (X1), the findings indicated that $3,57 \%$ of lecturers were included in a somewhat low category with the score interval between 2, 13 and 2, 54, while $25 \%$ of lecturers were included in the medium category with the score interval between 3, 37 and 3, 79. For the high category, only $2,14 \%$ of lecturers were included in this category with the score interval between 5, 46 i 5, 88. The data indicated that the average of the score for the conscientiousness was 3,71 with the deviation standard of 0 , 70 , and with the maximum score of 5,46 and the minimum score of 2,13 . This finding revealed that the category of the lecturersôconscientiousness was medium.

In terms of the agreeableness (X2), the findings indicated that $2,86 \%$ of lecturers were included in a somewhat low category with the score interval between 2, 13 and 2, 51, while $19,29 \%$ of lecturers were included in the medium category with the score interval between 4, 07 and 4, 46. For the high category, only $2,86 \%$ of lecturers were included in this category with the score interval between $5,24 \ddot{i} 5,86$. The data indicated that the average of the score for the agreeableness was 3,77 with the deviation standard of 0,73 , and with the maximum score of 5, 24 and the minimum score of 2,13 . This finding revealed that the category of the lecturersôagreeableness was medium.

With regard to the organizational climate (X3), the findings indicated that $6,43 \%$ of lecturers were included in a somewhat low category with the score interval between 2, 63 and 2, 93, while 20,71\% of lecturers were included in the medium category with the score interval between 3, 24 and 3, 54 . For the high category, only $5 \%$ of lecturers were included in this category with the score interval between 5, 07 ï 5, 38 . The data indicated that the average of the score for the organizational climate was 3,83 with the deviation standard of 0,59 , and with the maximum score of 5, 38 and the minimum score of 2,63 . This finding revealed that the lecturers felt that the organizational climate at the research site was medium. In terms of the job satisfaction (X4), the findings indicated that 1 , $43 \%$ of lecturers were included in a somewhat low category with the score interval between 2,13 and 2,49 , while $25 \%$ of lecturers were included in the medium category with the score interval between 3, 93 and 4, 29. For the high category, only 5, $71 \%$ of lecturers were included in this category with the score interval between 5,07 i 5,38 . The data analysis result indicated that the average of the score for the job satisfaction was 4,00 with the deviation standard of 0,67 , and with the maximum score of 5,38 and the minimum score of 2,13 . This finding revealed that the lecturersô job satisfaction at the research site was better. For the organizational commitment (X5), $5 \%$ of lecturers were included in a somewhat low category with the score interval between 2, 63 and 2, 93, while $24,9 \%$ of lecturers were included in the medium category with the score interval between 3, 54 and 3, 85. For the high category, 4, $29 \%$ of lecturers were included in this category with the score interval between 5, 07 i 5, 38. The data analysis result indicated that the average of the score for the organizational commitment was 3,86 with the maximum score of 5, 38 and the minimum score of 2, 63. This finding revealed that the lecturersô organizational commitment at the research site was medium.

Additionally, in this study to measure the relationship among the variables including the conscientiousness (X1), the agreeableness (X2), the organizational climate (X3), the job satisfaction (X4), and the organizational commitment (X5), the following path models were used to describe the relationship among the variables: 
Fig. 1. The path modelôs Coefficient value on the relationship among variables

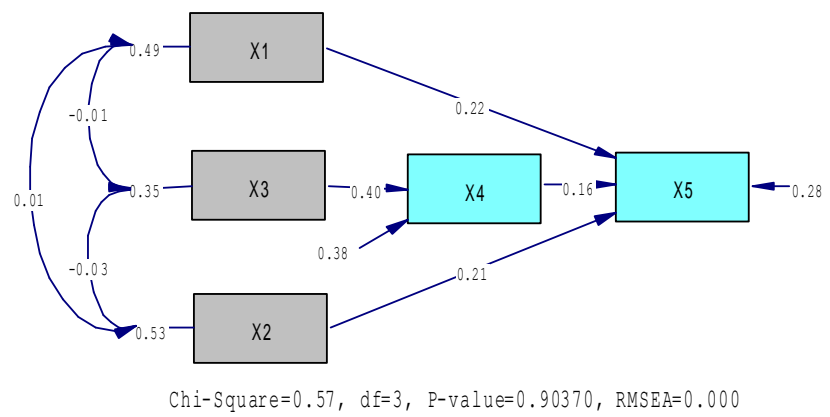

Fig. 2. The T-Value on the model of the structural relationship among the variables

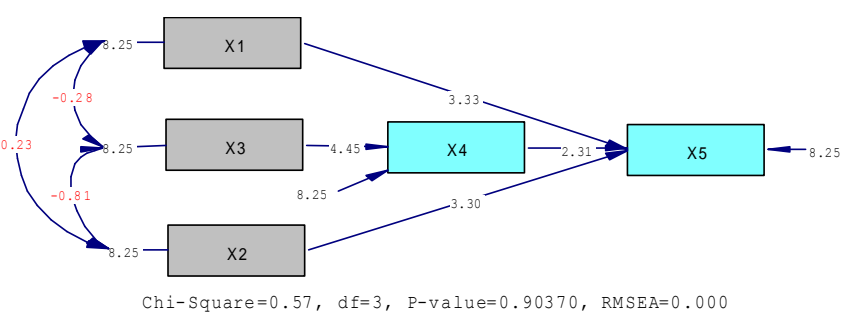

Based on the data analysis on Figure 1, the path coefficient value on the relationship among variables, the biggest path coefficient was the change effect of organizational climate on job satisfaction with a path coefficient value of 0,45 . This suggested that the factor that encouraged job satisfaction of lecturers at the research site was organizational climate. In the meantime, the path coefficient value that determined lecturersô organizational commitment with a path coefficient value of 0 , 22 was conscientiousness, agreeableness with a path coefficient value of 0,21 , job satisfaction with a path coefficient value of 0,16 .

Additionally, Figure 2 describes t-value on the significance level of the causal-effect pattern among variables. It describes that the path coefficient value of the organizational climate on job satisfaction was the highest: 4,45 with $\alpha=0,05$. Also, the path coefficient value of the conscientiousness on the organizational climate was 3,33 , while the path coefficient value of the agreeableness on the organizational climate was 3,30 and the path coefficient value of the job satisfaction on the organizational climate was 2,31 .

The findings of this study revealed that there was an effect of conscientiousness, agreeableness, and job satisfaction as well as an indirect effect of organizational climate on lecturersô commitment to the university where they worked. The findings of the study were in line with what previous literature indicated that personal and environmental factors influenced organizational commitment [4] [5] [6] [7] [8]. This suggests that although a university is a kind of a professionally bureaucratic organization, lecturersô commitment to their university is influenced by the factors that are similar to any other organization. In this study, organizational commitment was influenced by personal factors such as conscientiousness, agreeableness as well as environmental factors such as job satisfaction and organizational climate. Another interesting finding in this study was that lecturersôcommitment to their university was determined by job satisfaction, which they perceived based on the situation or climate at their university. Particularly, lecturersôjob satisfaction was influenced by their satisfaction with leaders, colleagues, ways of communication, and facilities at the university or faculty. This finding was related to the so called ñsatisfaction-performance loop [3]. Additionally, the effect of organizational climate on their job satisfaction had the biggest coefficient path score, suggesting that job satisfaction was importantly influenced by organizational climate. The finding of this study also indicated that the highest coefficient path score that determined lecturersô commitment to their university was related to conscientiousness, followed by agreeableness and job satisfaction. The highest coefficient path score of conscientiousness also implied that lecturers at the research site met the requirements for becoming professional lecturers as mandated by the teacher and lecturer law of No. 14 in 2005.

In this study, it was also found that the significant effect of agreeableness indicated that lecturersô commitment to the university was impacted by the fit between lecturerô personality and their job. This finding supports what the literature says that the fit between personality and job has a significant correlation with job satisfaction and organizational commitment Hambleton, Kalliath, \& Taylor (2000).

The findings of the current study indicated that personal and environmental factors affect organizational commitment of lecturers at one public university in Jambi. The results of this study have implied that personal and environmental factors could become a trigger to improve the quality of the higher education through improving lecturersôcommitment to where they work. Lecturersô commitment is very needed to achieve the academic, social, and cultural purposes of higher education, in particular, in the era of globalization because competition among universities in Indonesia and in the world is very tight. The increase and improvement of lecturersô commitment through the improvement of conscientiousness and agreeableness traits and organizational climate and job satisfaction should be well- planned and well-focused. In other words, in the future, human development processes should not only provide young people with knowledge and experience, but also provide them with the theories and practices on the importance of the sense of belonging (commitment) to where they will work.

\section{CONCLUSION}

The purposes of this research were to verify the personality traits consisting of conscientiousness and agreeableness as personal factors along with job satisfaction and organizational climate as the environmental factors affect organizational commitment and to compare the organizational commitment of lecturers at one public university in Jambi. The findings of the study revealed that lecturersô organizational commitment 
was directly impacted by their conscientiousness, agreeableness, job satisfaction; meanwhile, the organizational climate indirectly influenced lecturersô organizational commitment at the research site. The findings of this study imply that lecturersô organizational commitment was significantly impacted by personal and environmental factors.

The findings of this study could be the sort of evidence necessary for university, faculty, and department leaders for providing support to improve lecturersô organizational commitment at their respective area of authorities. Also, it could be utilized by the university, faculty, and department leaders to provide programs and policies for the lecturers for anticipating the challenges and problems related to lecturersô organizational commitment. Additionally, related to the limitations of the study, despite the fact this study will potentially contribute the sort of evidence necessary for university, faculty, and department leaders for providing support to improve lecturersô organizational commitment at their respective area of authorities, participants in this study may not be representative of Indonesian lecturers. There may be differences of lecturersô organizational commitment experienced by Indonesian lecturers from one department to other departments and from one university to other universities. Future research may include a larger sample of Indonesian lecturers from different departments or universities. Additionally, in this study, only two personality traits were examined due to logistic limitations,; future research could include five personality traits to be researched quantitatively and qualitatively.

\section{REFERENCES}

[1] W.R. Easterly, The Elusive Quest for Growth: Economistsô Adventures and Misadventures in the Tropics. London: MIT Press, 2001

[2] World Bank., Constructing Knowledge Societies: New Challenges for Tertiary Education. 2002. Retrieved from http://www.worldbank.org/

[3] N. J. Allen, and P.J. Meyer, Commitment in the Workplace: Theory, Research, and Application. London: Sage Publication, 1997.

[4] J.W. Newstrom, and K. Davis, Perilaku dalam Organisasi. Jakarta: Penerbit Erlangga, 2006.

[5] P.T. Costa, and R.R. McCrae, ñRevised NEO Personality Inventory (NEO PI-R) and Neo Five-Factor Inventory (NEO-FFI)ò. Odessa, .Fl: Psychological Assessment Resources. Inc, 1991.

[6] K. Davis, and J.W. Newstrom, Human behavior at Work Organization Behavior. New York: McGraw, 2002.

[7] P.C. Morrow, and J.C. McElroy, ñWork Commitment and Job Satisfaction over Three Career Stageò, Journal of Vocational Behavior, 30, 1987, pp.330-346.

[8] R.M. Steers, and Lyman, ñAntecedents and Outcomes of Organizational Commitmentò, Administrative Science Quarterly 22, 1997, pp. 46-56.

[9] A.J. Hambleton, T. Kalliath, and. P. Taylor, ñCriterion-Related Validity of a Measure of Person-Job and Person-Organization Fitò New Zealand Journal of Psychology, 29(2), 1997, 80-85. 